\title{
O USO DE PROTETORES BUCAIS RELACIONADO COM A AUTO-ESTIMA DO ATLETA: UMA REVISÃO NARRATIVA
}

DOI: 10.22289/2446-922X.V3N2A1

\author{
Camila Lopes Veloso ${ }^{1}$ \\ Fernanda Nunes da Silva \\ Camila Ferreira Silva \\ Paulo César Freitas Santos-Filho \\ Victor da Mota Martins
}

\section{RESUMO}

Protetores bucais são equipamentos de segurança que visam a prevenção de traumas como concussão, laceração, luxação e perdas dentárias em esportes de contato. Os protetores bucais confeccionados pelos dentistas proporcionam melhor comodidade e segurança em treinos, jogos e lutas. Esta revisão de literatura bibliográfica, de forma narrativa, tem como objetivo orientar cirurgiões-dentistas sobre as técnicas corretas de confecção de protetores bucais, melhorando a autoestima e autoconfiança do atleta com a intervenção odontológica. Os resultados das pesquisas apontam que os cirurgiões dentistas devem confeccioná-los de modo que os atletas se sintam confortáveis ao usá-los, quanto a respiração, fala e deglutição. Para aqueles atletas que já sofreram trauma de origem dental e se reestabeleceram, o protetor atua sendo benéfico para evitar um novo acidente, além de aumentar a confiança do esportista ao exercer suas atividades. Ainda há muitas dúvidas sobre a técnica de confecção dos protetores bucais individualizados, porém o objeto em questão é fundamental para esportistas, pois reduzem em até $80 \%$ a chance de trauma dento alveolar e maxilo-facial.

Palavras-chave: protetor bucal; prevenção; traumatismo dento-alveolar.

\section{ABSTRACT}

Mouth guards are safety equipment that aim to prevent trauma such as concussion, laceration, dislocation and dental losses in contact sports. The mouth guards made by dentists provide better comfort and safety in training, games and fights. This narrative review of bibliographic literature aims to guide dental surgeons about the correct techniques of confection of mouthguards, improving the self-esteem and self-confidence of the athlete with the dental intervention. The results of research indicate that dental surgeons should make them so that athletes feel comfortable using them, such as breathing, speech and swallowing. For athletes who have already suffered trauma of dental origin and have reestablished, the protector acts

\footnotetext{
${ }^{1}$ Endereço eletrônico de contato: camilav152@hotmail.com
}

Recebido em 07/06/2017. Aprovado pelo conselho editorial para publicação em 25/08/2017.

Rev. Psicol Saúde e Debate. Dez., 2017:3(2):1-14. 
to be beneficial to avoid a new accident, in addition to increasing the confidence of the sportsman when carrying out his activities. There are still many doubts about the technique of making individualized mouthguards, but the mouthguards is fundamental for sportsmen, as they reduce the chance of dentoalveolar and maxillofacial trauma by up to $80 \%$.

Key words: mouth guard; prevention; dento-alveolar trauma.

\section{INTRODUÇÃO}

O aumento da prática esportiva de esportes de contato como box, artes marciais, hóquei e rúgbi elevou o número de traumas do complexo dento-maxilo-facial. Em consequência a procura por protetores bucais também cresceu (Lima \& Mohn Neto, 2015).

Existem três tipos de protetores bucais disponíveis no mercado. O tipo I geralmente é encontrado em lojas de materiais esportivos, são chamados de "estoque" ou universais. O Tipo II é um protetor termoplástico ou termo ajustável, já o tipo III são protetores chamados de individualizados e feitos pelos cirurgiões dentistas. Visto que o tipo III é o de melhor retenção e comodidade por ser feito sob medida para cada esportista (Cavalvanti et al., 2012).

Equipamentos como protetores bucais, capacetes e máscaras faciais reduzem em até $80 \%$ a possibilidade de trauma facial. O uso dos protetores bucais diminui as chances de lesões orofaciais, concussões cerebrais, hemorragias e perda da consciência durante a prática de atividades físicas. Sendo assim, são de suma importância para prevenção de acidentes visando o cuidado com os atletas. Segundo Costa, o protetor ideal deve apresentar maior comodidade, facilidade ao falar, resistência a fratura, facilidade de respiração e proteção dos dentes-lábios (Costa et al., 2015).

Muitos atletas negligenciam o uso dos protetores bucais mesmo sabendo da sua importância. Eles relatam que não conseguem adaptar-se com o mesmo devido a sensação de falta de respiração e deglutição prejudicada. A odontologia acompanhada de outras áreas da saúde procura melhorar o rendimento dos esportistas contribuindo para a promoção e prevenção da saúde. Visto que, um protetor bem adaptado e confeccionado sob medida não causa desconforto para o atleta (Barberini, Aun Caldeira 2002; Silveira et al., 2009).

A odontologia desportista visa o atendimento específico para atletas. Entretanto, todos os Cirurgiões-dentistas estão aptos a tratar e prevenir lesões que os esportistas possam apresentar, sejam elas em ossos, dentes ou tecidos moles. É de suma importância que os dentistas em geral tenham conhecimento da técnica de confecção dos protetores bucais visto que estes são indispensáveis para atletas de contato físico (Junior PA, Souza DVAN, Galvão MX e Carvalho RWF 2013).

Rev. Psicol Saúde e Debate. Dez., 2017:3(2):1-14. 
O atleta ao usar protetores bucais está sendo beneficiado fisicamente e psicologicamente, pois os mesmos, bem adaptados, evitam traumas e aumentam a autoestima e confiança do esportista. Este estudo tem como objetivo orientar cirurgiõesdentistas sobre as técnicas corretas de confecção de protetores bucais. Sucedido por meio de revisão bibliográfica de forma narrativa, realizada nas bases de dados (SCIELO e Pubmed). Foram utilizados artigos publicados no idioma português e inglês por meio das seguintes palavras chaves: protetor bucal, prevenção, traumatismo e trauma dentoalveolar.

\section{TÉCNICA DE CONFECÇÃO E REFLEXÕES}

Os protetores bucais do tipo III individualizados pelos dentistas são equipamentos que proporcionam melhor comodidade e segurança em treinos, jogos e lutas (Lima \& Mohn Neto, 2015).

Os cirurgiões dentistas devem confecciona-los de modo que não atrapalhe a respiração, fala ou deglutição (Lima \& Mohn Neto, 2015).

Para confecção dos protetores bucais tipo III, os cirurgiões-dentistas devem fazer o uso de materiais tais quais: alginato de boa qualidade; gesso pedra tipo IV; 2 placas de EVA de espessura 3 mm e uma máquina plastificadora a vácuo (Lima \& Mohn Neto, 2015).

Abaixo será relatada de forma detalhada toda a técnica de confecção de protetores bucais tipo III:

1- Seleção da moldeira de estoque superior, de acordo com o tamanho ideal para cada paciente (Veríssimo et al., 2015).

2- Realizar a individualização da moldeira com cera, para cópia detalhada dos rebordos (Veríssimo et al., 2015).

3- Molda-se com alginato, copiando todo o fundo de saco de vestíbulo, freios, proeminências e sulcos da maxila (Veríssimo et al., 2015).

4- Desinfecção do molde com hipoclorito de sódio a 1\% (Veríssimo et al., 2015).

5- Vazar o gesso tipo IV com vibração evitando futuras bolhas no modelo (Veríssimo et al., 2015; Coto NP et al., 2014).

6- Delimita-se com um lápis todo o fundo de sulco, estendendo a marcação em 10 mm de distância dos dentes e palato. (Gonçalves et al., 2012; Santiago et al., 2008).

7- Em seguida o modelo deve ser submetido a corte, removendo a parte central do palato e excessos na face vestibular. (Figura 1) (Gonçalves et al., 2012). 


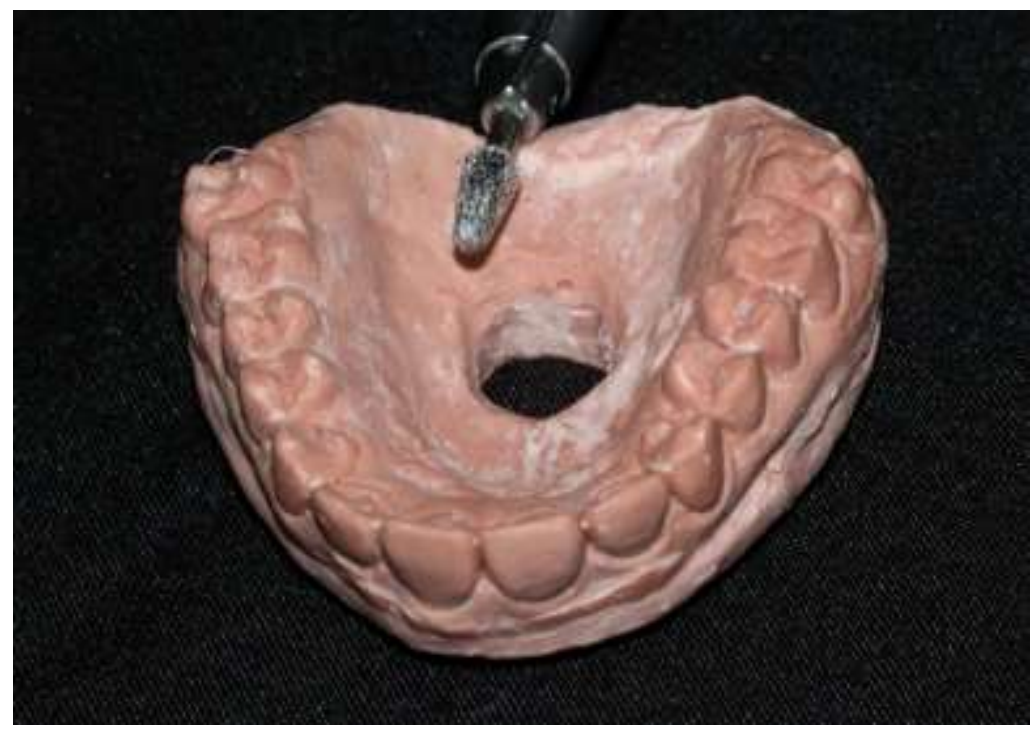

Figura 1: Corte do modelo.

8- O modelo deve ser posicionado no centro da plastificadora. (Figura 2) (Gonçalves et al., 2012; .Coto NP et al., 2014)

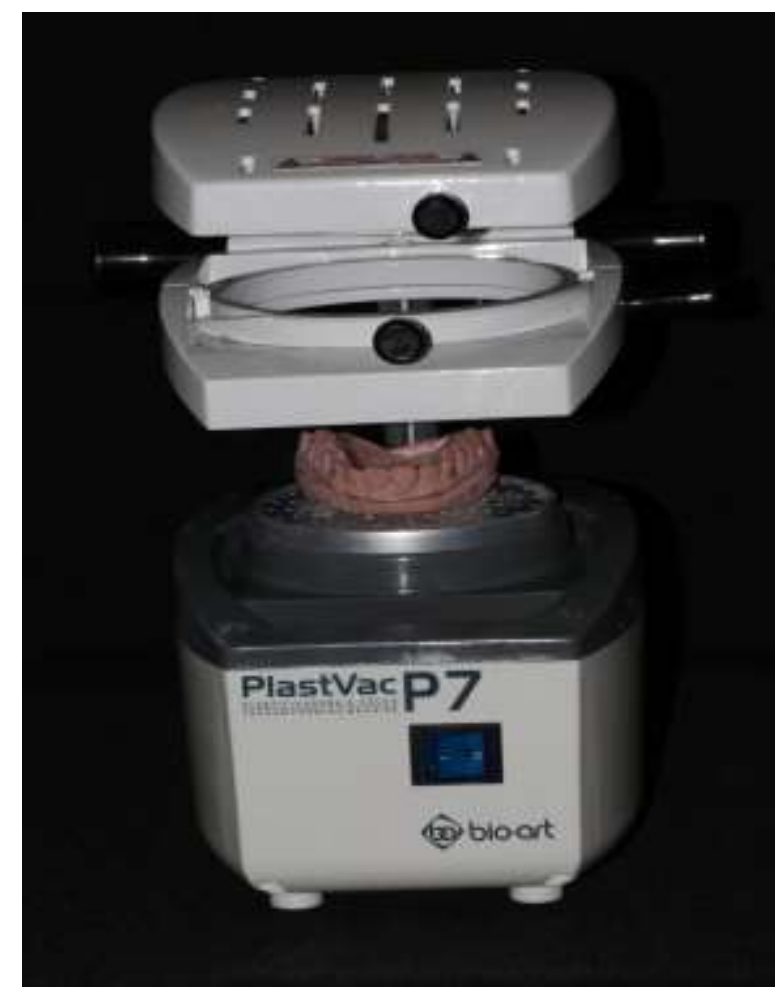

Figura 2: Posicionamento do modelo na plastificadora.

9- A primeira placa de EVA de $3 \mathrm{~mm}$ deve ser colocada em posição. (Figura 3) (Leone et al., 2014)

Rev. Psicol Saúde e Debate. Dez., 2017:3(2):1-14. 


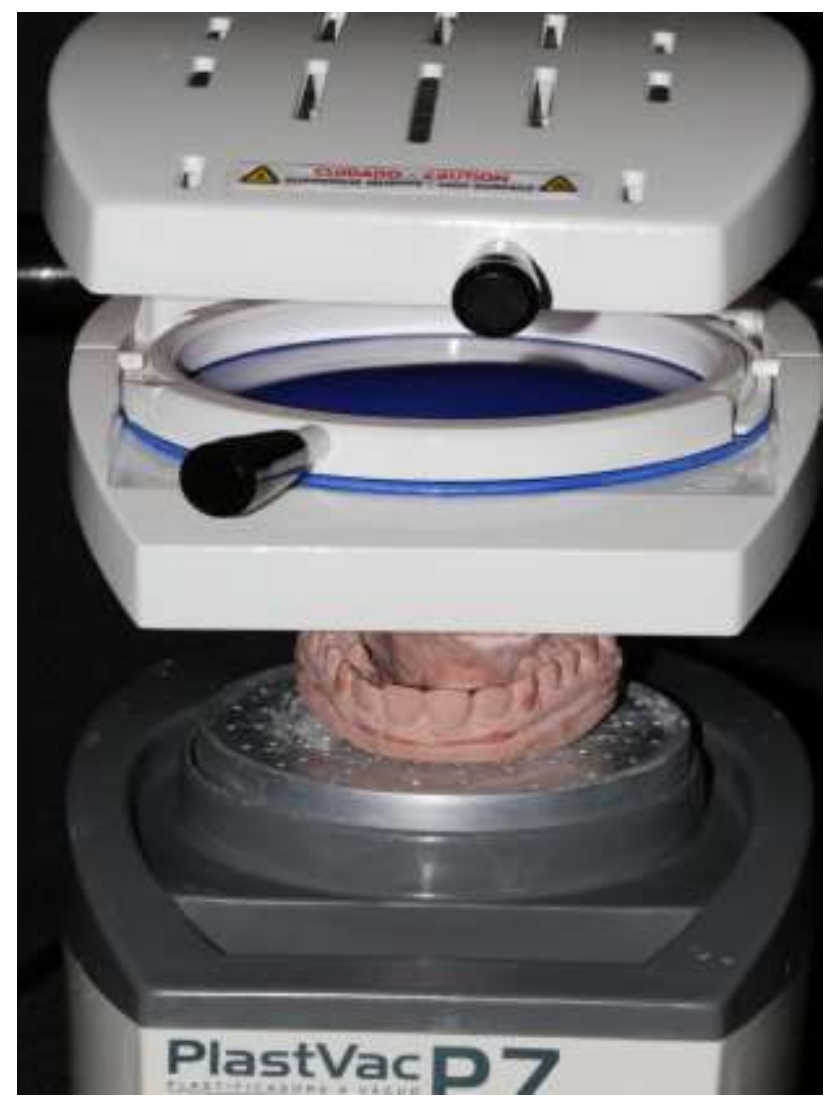

Figura 3: Ajuste da placa de EVA.

10- De acordo com Bastos, a placa deve ser aquecida a $120^{\circ}$ C. (Figura 4) (Mizuhashi F \& Koide 2016)

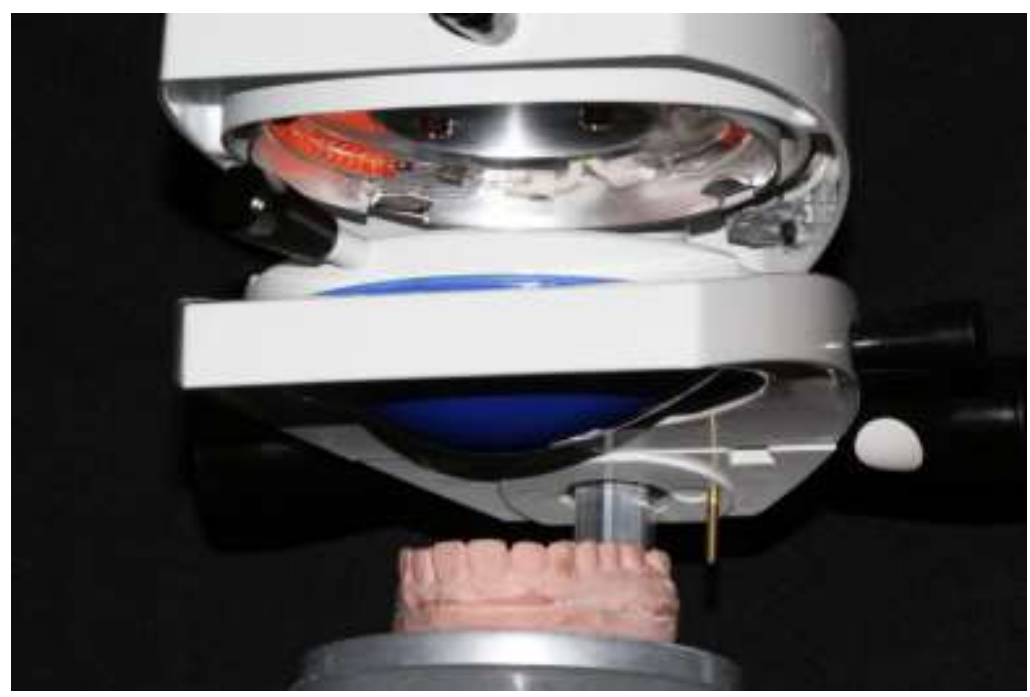

Figura 4: Aquecimento da placa.

Rev. Psicol Saúde e Debate. Dez., 2017:3(2):1-14. 
11- O vácuo deve ser aplicado durante 2 min. (Figura 5) (Coto NP et al. 2014)

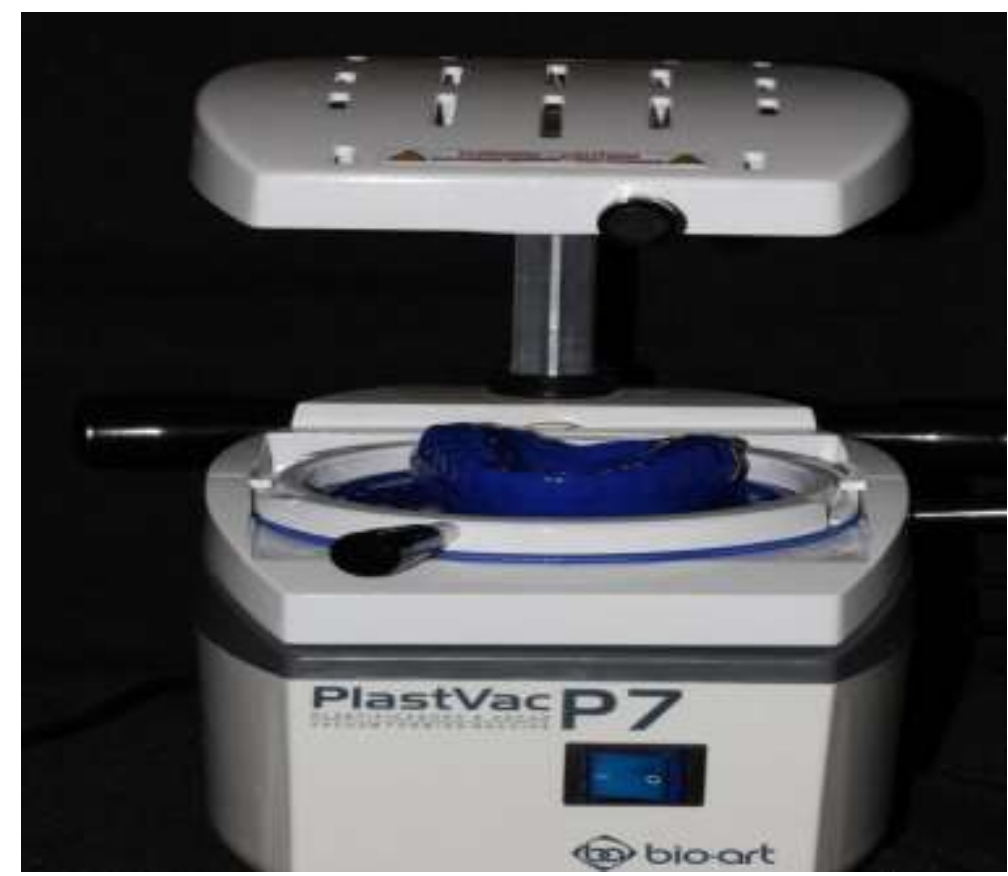

Figura 5: Aplicação do vácuo à placa.

12- Após 1 hora de resfriamento a placa deve ser cortada respeitando o limite de $3 \mathrm{~mm}$ na face vestibular. (Figura 6) (Mizuhashi F \& Koide 2016)

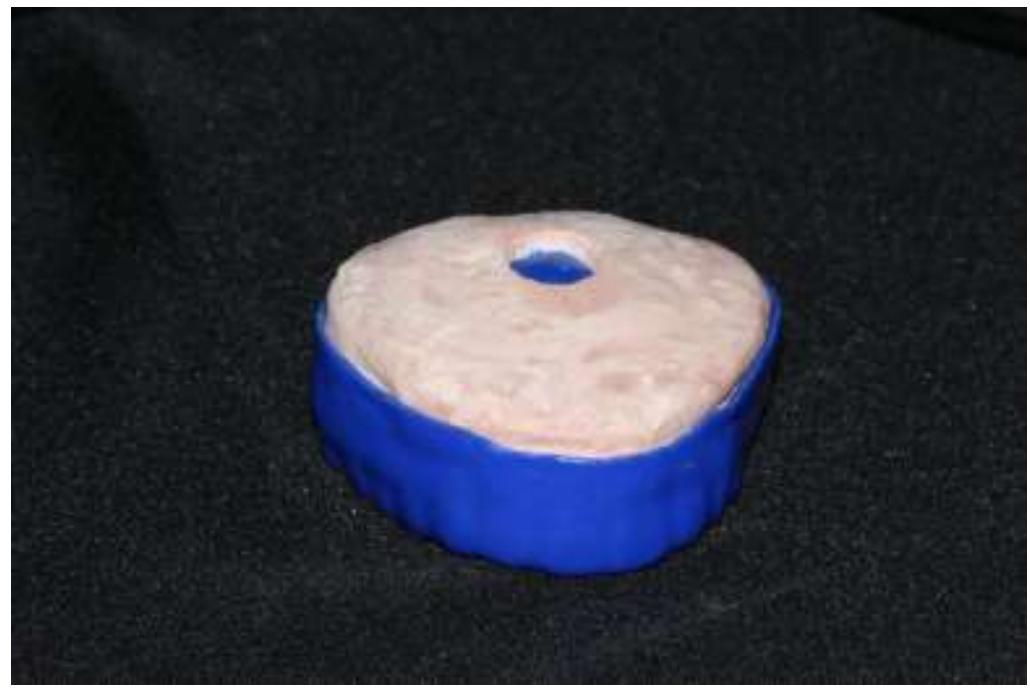

Figura 6: Resfriamento da placa.

Rev. Psicol Saúde e Debate. Dez., 2017:3(2):1-14. 
13- Na face palatal deve ser respeitado o limite de 10mm. (figura 7) (Leone et al., 2014)

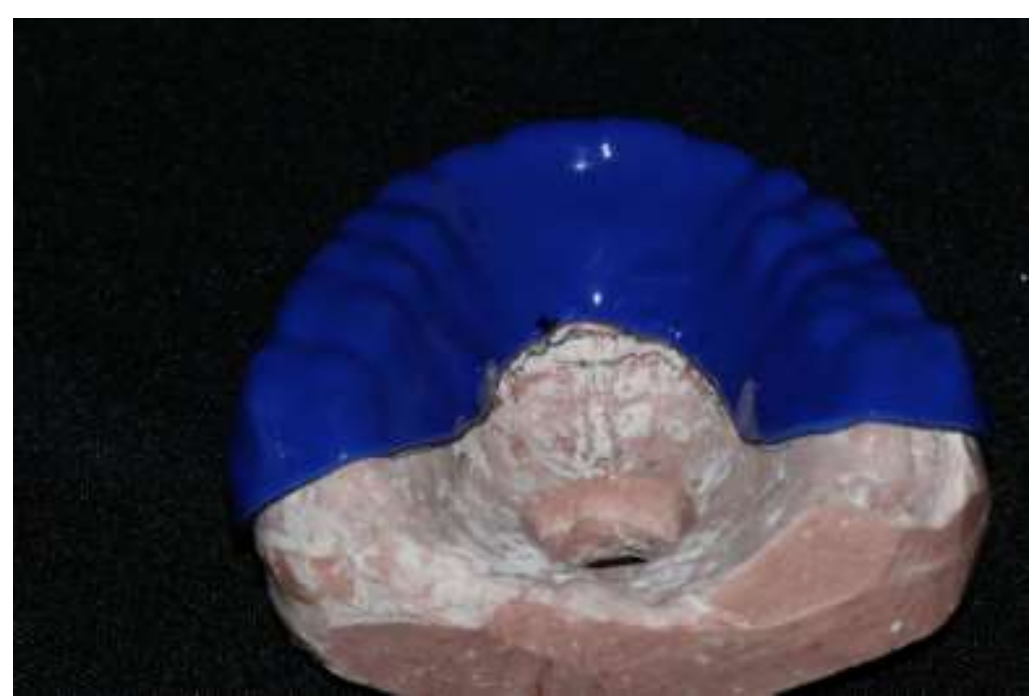

Figura 7: Detalhe da face palatal.

14- A segunda folha também de espessura $3 \mathrm{~mm}$ deve ser colocada em posição e então submetida as mesmas temperaturas e tempo de vácuo. (Figura 8) (Mizuhashi F \& Koide 2016)

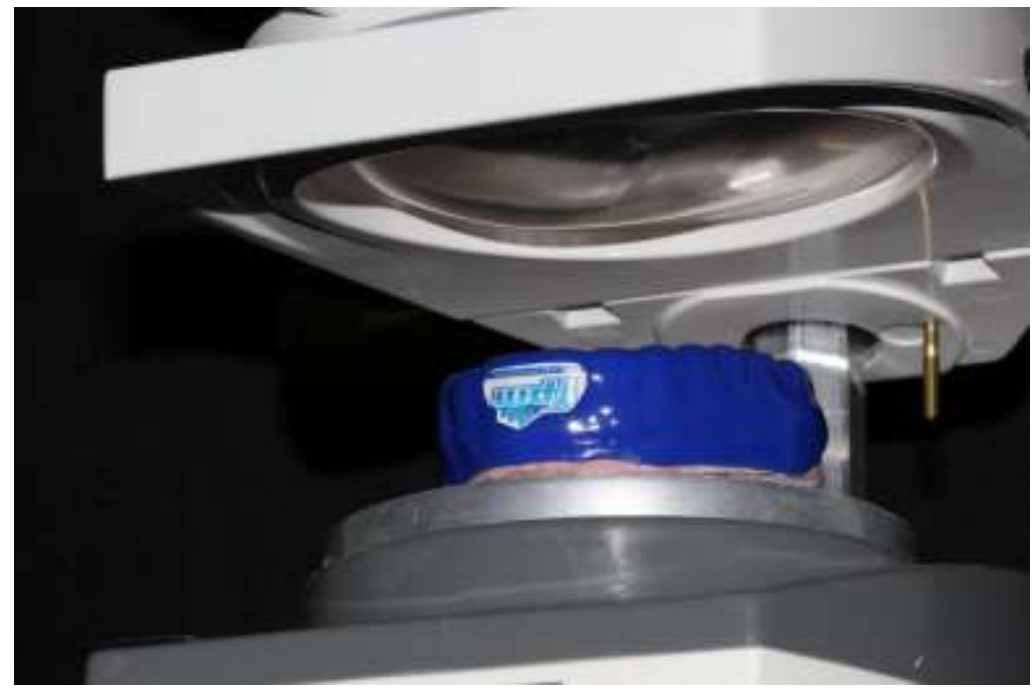

Figura 8: Segunda folha submetida a aumento da temperatura e vácuo.

15- O recorte da segunda placa deve ser realizado com auxílio de bisturi e lecron (Santiago et al., 2008). 
16- Após o recorte das margens a superfície oclusal deve ser aquecida com uma lâmpada a álcool e o paciente deve morder para que os contatos de oclusão fiquem devidamente distribuídos (figura 9) (Coto NP et al., 2014).

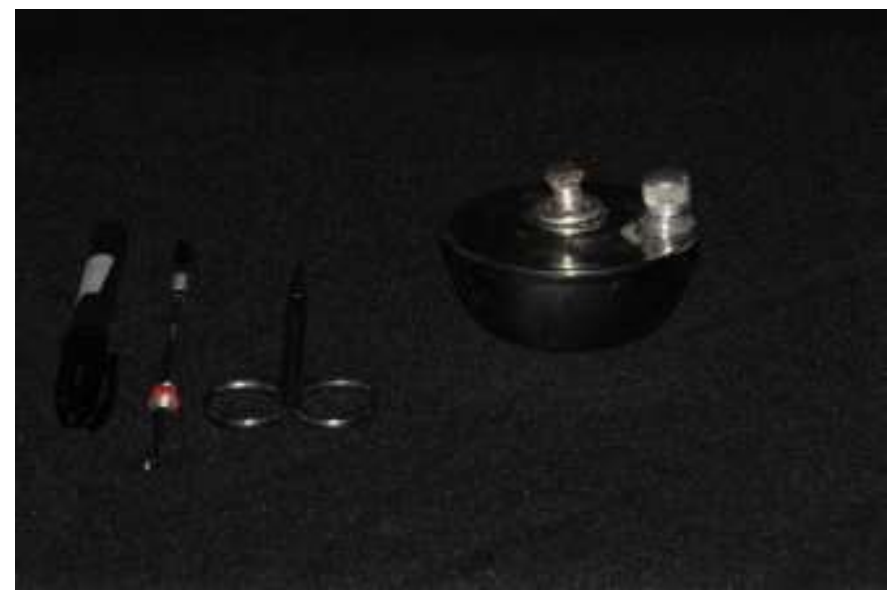

Figura 9: Lâmpada a álcool e instrumentos para ajuste.

17- Após o protetor ser colocado em posição os freios e proeminências devem ser avaliados pelo cirurgião-dentista de acordo com o relato do paciente. Se houver relato dor ou incomodo em algum ponto específico deve ser desgastado no protetor para evitar lacerações. O protetor deve ser confortável o suficiente para que o atleta tenha boa adaptação. (figura 10) (Coto NP et al., 2014).

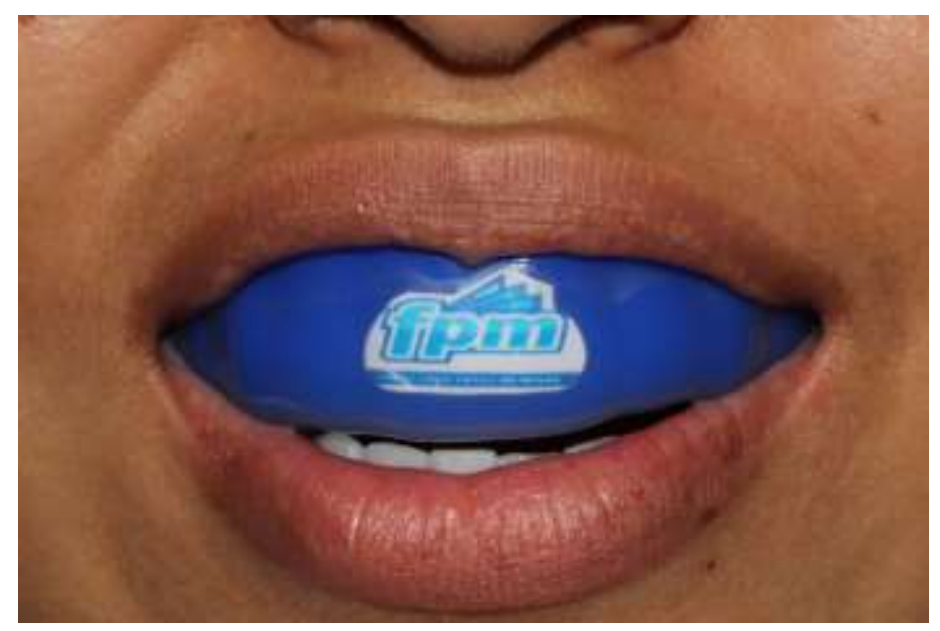

Figura 10: Protetor colocado em paciente.

Rev. Psicol Saúde e Debate. Dez., 2017:3(2):1-14. 
18- O acabamento e polimento deve ser realizado de modo que deixe as bordas do protetor lisas sem pontas que possam lesionar a mucosa dos atletas, devem ser feitas com o auxílio de uma broca Maxicut e pontas para polimento (Coto NP et al., 2014).

19- Deve-se fazer os ajustes oclusais necessários, visando o encaixe perfeito na cavidade bucal do paciente (Coto NP et al., 2014).

20- O protetor bucal após instalado deve promover o selamento labial de modo que não atrapalhe a respiração, fala ou deglutição do paciente (Coto NP et al., 2014).

Alguns fatores tais como: tempo de aquecimento da plastificadora, profundidade palatal do modelo de gesso, experiência do operador, altura e orientação do modelo sobre a plastificadora, podem influenciar na espessura final no protetor bucal. Farrington demonstrou em seu estudo que a deformação do protetor pode variar de 26 a $45 \%$ da espessura inicial. Sendo assim o protetor bucal pode diminuir até $1 \mathrm{~mm}$ de espessura em média após sua deformação plástica. Este fato faz com que duas placas de $3 \mathrm{~mm}$ sejam usadas para que no final a espessura de $4 \mathrm{~mm}$ seja encontrada (Farrington et al. 2016).

O material de escolha para confecção, deve promover estabilização dos maxilares, ser flexível de modo que absorva os impactos gerados pelos golpes e resistente o suficiente para evitar perfurações provocadas pelas cúspides dos dentes anteriores e posteriores. Usualmente os cirurgiões dentistas optam pelo copolímero de polietilenopolivinilacetato (EVA) que é um polímero de natureza não tóxica, de fácil produção, apresentando boa histocompatibilidade e elasticidade visando absorção dos impactos. Santiago mostra em seu artigo que as borrachas de silicone também são materiais que podem ser usados para confecção dos protetores por possuir melhores propriedades elásticas e por serem mais agradáveis ao toque embora outro estudo demonstre que os protetores feitos com EVA sob pressão, apresentam uma espessura mais adequada. Porém, em relação ao conforto do paciente em questão, o EVA apresenta melhores resultados (Santiago et al., 2008).

Espessuras mais grossas como de $6 \mathrm{~mm}$ por exemplo podem gerar maior tensão entre lábio e bochecha aumentando o risco de lesões em tecidos moles e dificultando a barreira natural de proteção dos dentes que é feita por estes. Além do desconforto, o protetor de espessura $6 \mathrm{~mm}$ pode causar dificuldade respiratória e pouca aceitação entre os atletas. Estudos demonstram que a espessura ideal para confecção dos protetores bucais em uma escala de 1 a $6 \mathrm{~mm}$, é de $4 \mathrm{~mm}$ (Farrington et al., 2016). Visto que testes em elementos finitos foram feitos e os protetores com espessuras menores que $3 \mathrm{~mm}$ apresentam deslocamento após força aplicada, além de apresentarem menor absorção de impacto. Sendo assim ocorre transmissão do golpe para os dentes e estruturas adjacentes. Porém, mesmo apresentando 
menor absorção e menos preciso que os protetores de $4 \mathrm{~mm}$, eles protegem o conjunto dentoalveolar e obviamente apresentam melhores resultados que sem o uso de nenhum protetor. Os protetores de $4 \mathrm{~mm}$ reduzem os valores de tensão e deformação na superfície coronária e estruturas adjacentes e diminuem o risco de subluxação e concussão cerebral (Farrington et al., 2016; Santiago et al., 2008).

Os atletas podem escolher o tipo de protetor bucal que preferem usar, geralmente por serem mais baratos os protetores tipo I geralmente são chamados de "estoque" ou universais. O Tipo II é um protetor termoplástico ou termo ajustável, já o tipo III são protetores chamados de individualizados e feitos pelos cirurgiões dentistas (Junior et. al., 2013).

O tipo I, de estoque é encontrado com bastante frequência em lojas de materiais esportivos e até mesmo em farmácias, são encontrados nos tamanhos pequeno, médio ou grande. Porém, não possuem adaptabilidade suficiente, são volumosos, desconfortáveis, ficam retidos apenas com os arcos ocluídos, não possuem resiliência e proteção desejada (Junior et. al., 2013).

O tipo II termoplástico também é encontrado com frequência em lojas de materiais esportivos e farmácias. Entretanto, difere-se do tipo I por possuir uma melhor capacidade de adaptação. Quando aquecido em água quente, o material se torna maleável atingindo uma deformação elástica, onde é levado à cavidade bucal para tomar presa, onde atinge a deformação plástica e consequentemente sua forma final. Mesmo possuindo propriedades que o tonem mais adepto à cavidade bucal que o tipo I, o tipo II não é o mais indicado pois pode causar queimaduras se for levado a cavidade bucal em altas temperaturas, podendo também causar disfunção temporomandibular por ignorar a posição condilar (Bastos et al., 2013).

Já os protetores tipo III individualizados são protetores confeccionados pelos cirurgiões-dentistas, que proporcionam aos atletas melhor comodidade, adaptação, conforto, estabilidade e retenção. Além de causar menos interferência na fala, na respiração e na deglutição. Podem ser indicados para esportistas de qualquer idade inclusive aqueles que fazem uso de aparelhos ortodônticos fixos ou com dentes em erupção. Porém, são menos utilizados por exigirem do atleta um gasto financeiro mais alto devido as despesas com o cirurgião dentista. Para praticantes de esportes de contato que fazem uso de aparelhos ortodônticos fixos o protetor deve ser confeccionado tanto para a arcada superior quanto inferior. Visto que a probabilidade de laceração de lábio e bochecha é maior para esse grupo específico de atletas (Gonçalves et al., 2012).

Existem três fatores predisponentes para o traumatismo dentário em esportes de contatos: atletas que possuem overjet acentuado, maloclusão classe II de Angle, lábio 
superior curto e atletas respiradores bucais. Estes estão mais susceptíveis a traumas do complexo dento-maxilo-facial, sendo de maior importância a utilização de protetores personalizados (Wang e Pradebon, 2003).

Os traumatismos dentários e faciais podem ser leves, moderados ou severos. Por isso são classificados em uma ordem crescente de acordo com o seu grau de severidade, como: a concussão, subluxação, luxação extrusiva, luxação lateral, luxação intrusiva e por último a avulsão (Wang e Pradebon, 2003).

Os traumas provocados pelos golpes de lutas e treinos, gera no atleta um prejuízo físico e psicológico, onde a intervenção do cirurgião dentista na prevenção de traumas faz com que o atleta se sinta confiante ao praticar algum tipo de atividade física. Lesões como, concussão cerebral, hemorragias, fraturas e avulsões dentárias podem prejudicar a autoestima do atleta e até mesmo interromper sua carreira. Para promover a saúde bucal dos esportistas, o cirurgião dentista deve trabalhar eliminando os riscos, desenvolvendo protocolos de prevenção periódicos e mantendo um bom estado dos protetores bucais. (Gonçalves et al., 2012; Veríssimo et al. 2015)

Em caso mais simples de trauma dento alveolar, materiais restauradores, provisórios e definitivos, diretos e indiretos, são utilizados para reestabelecer função e estética do paciente (Borges et al., 2017). Para os pacientes que possuem restaurações anteriores, o uso do protetor é imprescindível, ou seja, precisam fazer o uso regularmente, pois o dente hígido possui maior resistência ao impacto que o dente restaurado (Veríssimo et al. 2015; Veríssimo et al. 2016). Em casos mais complexos, a disfunção temporomandibular (DTM) é provocada, apresentando dor mio facial, deslocamento de disco, dores nas articulações ou inflamação. A DTM pode ser constatada a partir da presença de ruído, crepitação, magnitude reduzida de movimentos bem como anomalias, associadas na mastigação, zumbido no ouvido, fadiga durante a mastigação, mordida desconfortável, edema e assimetria na face e desgaste dentário (Braga e Souza 2016).

Para praticantes de esportes de contato que fazem uso de aparelhos ortodônticos fixos o protetor deve ser confeccionado tanto para a arcada superior quanto inferior. Para sua confecção a moldagem com alginato deve ser realizada e no modelo de gesso o aparelho deve ser coberto com uma borracha de silicone, isto faz com que um espaço livre entre o protetor e aparelho seja mantido. Após a plastificação do protetor esse espaço livre é preenchido com material de reembasamento provisório e recoberto com Fluoropolímero em $85 \%$ de etilacetato. A probabilidade de laceração de lábio e bochecha é maior para esse grupo específico de atletas por isso os protetores confeccionados pelos cirurgiões dentistas deve ser a primeira escolha. Porém, o protetor deve ser ajustado a cada 2 a 3 semanas para que 
não atrapalhe na movimentação ortodôntica (Gonçalves et al., 2012; Veríssimo et al., 2016; Wang e Pradebon, 2003).

O uso dos protetores na prática desportiva deve ser estimulado desde a infância entre crianças e adolescentes, para que eles se acostumem com o uso frequente destes (Silveira et al., 2009).

Segundo Wang, os protetores ao serem confeccionados devem seguir algumas regras básicas, visto que a espessura na vestibular deve ser de $4 \mathrm{~mm}$, a palatina deve apresentar $2 \mathrm{~mm}$ e a oclusal $3 \mathrm{~mm}$ de espessura. Ele deve terminar a $3 \mathrm{~mm}$ da gengiva marginal vestibular e $10 \mathrm{~mm}$ da gengiva marginal palatina (Wang e Pradebon, 2003).

Alguns cuidados básicos devem ser tomados para que os protetores tenham vida útil maior. Eles devem ser lavados com água morna ou fria, sempre escovados com creme dental e armazenados em caixas que contenham perfurações para o ar atravessar e promover oxigenação adequada a fim de evitar colonização de bactérias em seu interior. Após cada treino, jogo ou competição o protetor deve ser avaliado cuidadosamente. Se for observado fraturas, trincas ou apresentar deformação ele deve ser substituído (Wang e Pradebon, 2003).

\section{CONSIDERAÇÕES}

Os cirurgiões dentistas possuem a função de levar a informação para os atletas sobre a importância do uso de protetores bucais. Uma equipe multidisciplinar condiciona os atletas da melhor forma possível visando a diminuição de traumas da face. Os protetores bucais tipo III devem ser a primeira escolha dos esportistas por possuírem características físicasmecânicas próprias que permitem a prevenção de lesões. Por isso o objetivo deste trabalho foi informar sobre a técnica de confecção ideal orientando os cirurgiões dentistas em futuros tratamentos odontológicos preventivos reestabelecendo a confiança do atleta na busca pela proteção do complexo dento-maxilo-facial.

Rev. Psicol Saúde e Debate. Dez., 2017:3(2):1-14. 


\section{REFERÊNCIAS}

Barberini AF, Aun CE, Caldeira CL. (2002). Incidência de injurias orofaciais e utilização de próteses bucais em diversos esportes de contato. Odontol Unicid, 14(1):7-14.

Bastos da RS, Vieira EMM, Simões CAD, Peres DSHCS, Caldana ML, Lauris JRP. (2013). Odontologia desportiva: proposta de um protocolo de atenção à saúde bucal do atleta. Gaúch . Odontol, 61(1)

Borges SX, Oliveira ALA, Goes RWL, Nascimento F, Silva CF, Santos-Filho PCF, Martins VM. (2017). Materiais restauradores utilizados nas Unidades básicas de saúde de um Municipio de pequeno porte na região alto Paranaíba do estado de Minas Gerais. Revista Psicologia e Saúde em Debate, 3(1):22-33.

Braga AC, Souza FLD. (2016). Transtornos psicológicos associados à disfunção temporomandibular. Revista Psicologia e Saúde em Debate, 2(1):100-120

Cavalvanti AL, Santos FG, Peixoto LR, Gonzaga AKG, Dias CHS, Xavier AFC. (2012). Ocorrências de injurias orofaciais em praticantes de esportes de luta. Pesq Bras Odontoped Clin Integ,12(2):223-8.

Costa SS, Maia de DAC, Costa IIS, Netto CJFC, Feitosa EA, Venâncio AEF. (2015). Odontologia desportiva: melhor performance com a atuação do dentista na pratica da atividade física. Coleção pesquisa em educação física,14(4):131-8.

Coto NP, Gialain IO, Batista Filho MO, Dias RB. (2014). Protetor Bucal individualizado, para esporte, especifico para Ortodontia. Assoc. Paul. Cir. Dent. 68(2)

Farrington T, Coward T, Pearson GO, Taylor RL, Earl P, Winwood K. (2016). An investigation into the relationship between thickness variations and manufacturing techniques of mouthguards. Dental Traumatology, 32:14-21.

Gonçalves AR, Albuquerque HCL, Ferreira MCC, Souza CHC. (2012). Protetores bucais: tipos e técnica de confecção. Prosthes. Lab. Sci, 2(5):61-68.

Junior PA, Souza DVAN, Galvão MX, Carvalho RWF. (2013). Conhecimento e utilização de protetor bucal entre praticantes de artes marciais. Cir.traumatol. buco-maxilo-fac, 3(3).

Leone CCL, Barros IRCN, Salles AG, Antunes LAA, Antunes LS. (2014). O uso do protetor bucal nas artes maciais: consciência e atitude. Rev Bras Med Esporte, 20(6).

Lima LF, Mohn Neto CR. (2015). Atenção ao trauma bucal: cotidiano e percepções de atletas do futebol. Odontol Bras Central, 26(69):54-6.

Mizuhashi F, Koide K. (2016). Appropriate fabrication method for vacuumformed mouthguards. Dental Traumatology, Apr;33(2):110-113.

Rev. Psicol Saúde e Debate. Dez., 2017:3(2):1-14. 
Santiago E, Simões R, Soares D, Pereira JA, Caldas T. (2008). Protetor Bucal "Custom-Made" Indicações, Confecção e Características Essenciais. Arquivos de Medicina, 22(1):25-33.

Silveira EG, Araújo de SN, Schimitt BHE, Farias MMAG, Campos L, Caregnato M. (2009). Conhecimento e atitudes dos odontopediatras do estado de Santa Catarina acerca de mecanismos de prevenção de traumatismos bucais relacionados a esportes. Odontologia da Unesp, 38(6):341-6.

Verissimo C, Costa PVM, Filho CFS, Tantbirojn D, Versluis A, Soares CJ. (2016). CustomFitted EVA Mouthguards: what is the ideal thickness? a dynamic finite element impact study. Dental Traumatology ; 32: 95-102;

Veríssimo C, Costa PVM, Soares PBF, Versluis A, Tantbirojn D, Soares CJ. (2015). Protetores bucais personalizados: aspectos clínicos e biomecânico. 11(3):280-287.

Wang J, Pradebon M. (2003). Protetores Bucais Para Prevenção De Traumatismo Dental. Dissertação, Universidade Federal de Santa Catarina.SC. Brasil. 